BIOTROPIA (2) 1988/1989: 32-37

\title{
A COLLECTION OF TICKS (IXODIDAE) FROM SULAWESI UTARA, INDONESIA
}

\author{
L.A. DURDEN \\ Department of Entomology, NHB 165, Museum Support Center \\ Smithsonian Institution, Washington D.C. 20560, U.S.A. \\ C.H.S. WATTS \\ Division of Natural Science \\ South Australian Museum, North Terrace, Adelaide, \\ South Australia 5000, Australia
}

\begin{abstract}
Ixodid ticks were collected from seven species of endemic murid rodents and from vegetation in Sulawesi Utara, Indonesia. Adult ticks belonging to the species, Amblyomma babirussae, A. cyprium and Dermacentor (Indocentor) steini were taken from the vegetation. Immature ticks assignable to the genera, Haemaphysalis, Amblyomma and Ixodes infested the murids with Parauromys dominator and Maxomys musschenbroekii being the two most heavily tick-infested host species. The data are compared to other tick records from Sulawesi.
\end{abstract}

\section{INTRODUCTION}

Ectoparasites were collected from murid rodents live-trapped in Sulawesi Utara (North Sulawesi), Indonesia, on August 1985. We report here on the ticks (Ixodi-dae) collected during this project. Eighty five murids belonging to seven species, all endemic to Sulawesi, were examined for ticks. The comparatively small size of these host animals made infestation by adult ticks (which are identifiable to the species level) unlikely, so adult ticks were taken from vegetation when possible to supplement the collections. Collection data for the 58 ticks recovered from the murids and from vegetation are given below, listed by collection locality. Specimens are currently in the Rocky Mountain Laboratory collections (now at the Smithsonian Institution, Washington, Washington B.C., U.S.A.) and accession numbers are also given. Mammal specimens are either with collections of the South Australian Museum or the Museum Zoologicum Bogoriense, Indonesia; their original collection numbers are presented here.

1. Gunung Moajat $\left(0^{\circ} 45^{\prime} \mathrm{N} 124^{\circ} 25^{\prime} \mathrm{E}\right)$. Elevation, $1800 \mathrm{~m}$. From

- vegetation. Amblyomma cyprium Neumann (1Q) 
- Ex. Parauromys dominator (CHSW No. 114)

Haemaphysalis sp. (1L*)

2. Dumoga-Bone Nat. Park ( $\left.0^{\circ} 34^{\prime} \mathrm{N} 123^{\circ} 54^{\prime} \mathrm{E}\right)$. Elevation, $200-300 \mathrm{~m}$.

- On grass at forest edge Dermacentor (Indocentor) steini Schulze $\left(1^{\circ}\right)$

- Ex. Maxomys musschenbroekii (CHSW No. 19) Amblyomma sp. (4L, 2N*) Haemaphysalis sp. (1L)

- Ex. M. musschenbroekii (CHSW No. 21) Amblyomma sp. (3L)

- Ex. Rattus xanthurus (CHSW No. 28) Amblyomma sp. (IN) Amblyomma sp. (probably)(1N)

- Ex. Maxomys hellwaldii (CHSW No. 42) Haemaphysalis sp. (4N) (One specimen has three acaridid mites attached to its venter).

- Ex. Rattus hoffmanni (CHSW No. 47) Haemaphysalis sp. (1L, IN) Ex. $P$. dominator (CHSW No. 48) Amblyomma sp. $(12 \mathrm{~L}, \mathrm{IN})$

- Ex. M. musschenbroekii (CHSW No. 54) Ixodes sp. (2L)

- Ex. M. musschenbroekii (CHSW No. 55) Haemaphysalis sp. $(7 \mathrm{~N})$

- Ex. R. hoffmanni (CHSW No. 58) Ixodes sp. (1L)

- Ex. P. dominator (CHSW No. 66) Haemaphysalis sp. (IN)

- Ex. R. hoffmanni (CHSW No. 80) Ixodes sp. (IN)

3. Dumoga-Bone Nat. Park. Hog's Back Ridge $\left(0^{\circ} 35^{\prime} \mathrm{N} 123^{\circ} 52^{\prime} \mathrm{E}\right)$ Elevation, $490 \mathrm{~m}$.

- Ex. P. dominator Haemaphysalis sp. (IN)

- Ex. R. hoffmanni (CHSW No. 138) Amblyomma sp. (4L, $4 \mathrm{~N}-2$ of these nymphs belong to one species and 2 to a second species)

4. Gunung Mogogonipa ( $\left.0^{\circ} 27^{\prime} \mathrm{N} 123^{\circ} 57^{\prime} E\right)$. Elevation, $1008 \mathrm{~m}$.

- On vegetation 


\section{Amblyomma babirussae (19) Dermacentor (I.)}

steini Schulze (19)

5. By 'Lake' (044'N 124²7'E). Elevation, 1080-1200 m. - Ex. P.

dominator (CHSW No. 13) Haemaphysalis sp. (IN)

$* \mathrm{~L}=$ Larvae, $\mathrm{N}=$ Nymphs.

The three species of adult ticks that were collected are fairly well known. Amblyomma babirussae (Figure 1) represents part of the endemic tick fauna of

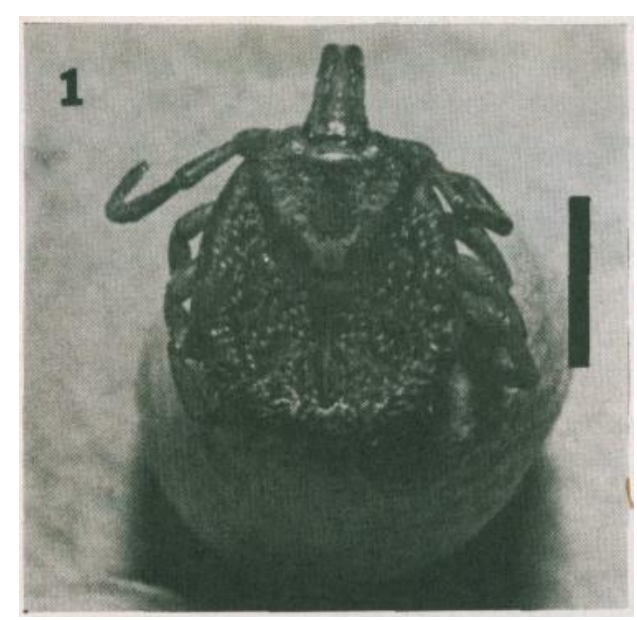

Figure 1. Amblyomma babirussae (adult female).

Sulawesi; adults are parasitic principally on larger artiodactyls and on endemic and feral pigs (Suidae) (Anastos 1950, Keirans and Robbins 1987) while immatures are parasitic on these same hosts and also on murids (Keirans and Robbins 1987, Van Peena et al. 1974). Adults of $A$. babirussae are also known to attach to humans (Keirans and Robbins 1987). Amblyomma cyprium (Figure 2) has a wide distribution in the Indo-Pacific region (Anastos 1950; Kohls 1957; Wilson 1969; Marshall 1976; Kemp and Wilson 1979) with adults again parasitic largerly on wild and feral pigs, but also on humans and cattle, and immatures on a variety of smaller hosts, 


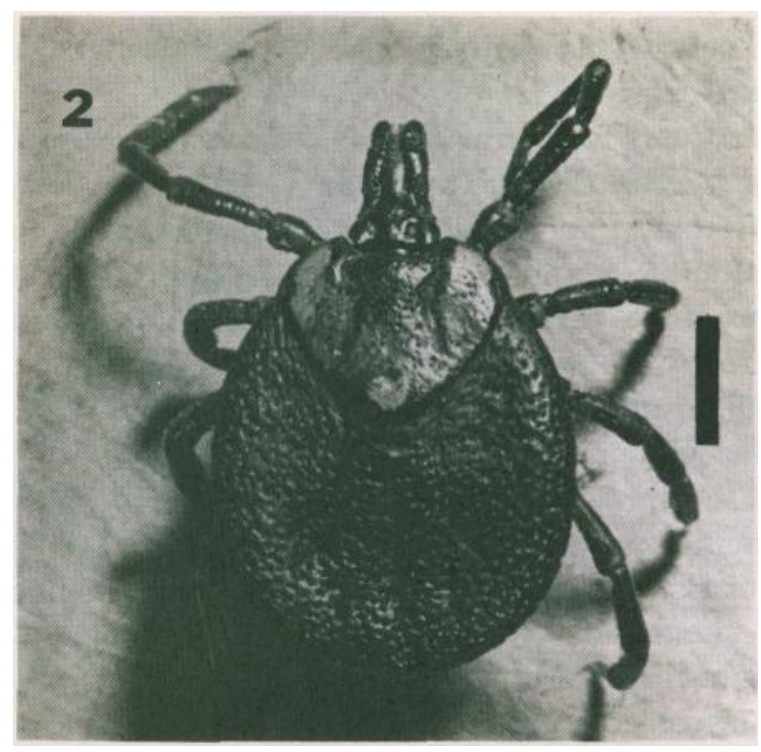

Figure 2. Amblyomma cyprium (adult female).

particularly murids (Kohls 1957; Kemp and Wilson 1979). Dermacentor (I.) steini (Figure 3) has recently been redescribed by Wassef and Hoogstraal (1986) who document a wide distribution for this species in Indo-Malaysia (including the Philippines and with establishment on Papua New Guinea); however, they give no records for Sulawesi so the present collections extend the documented range for this tick.

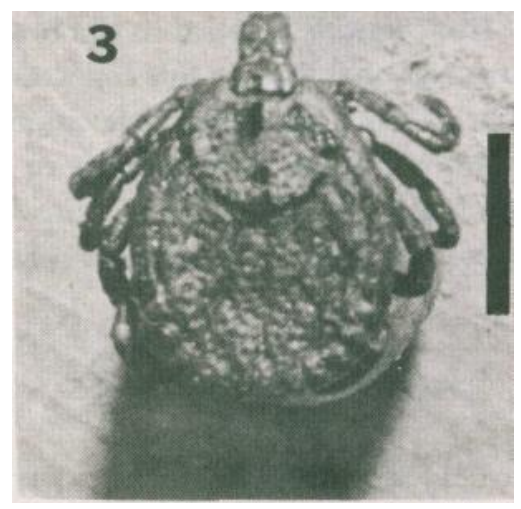

Figure 3. Dermacentor (Indocentor) steini (adult female). 
Dermacentor (I.) steini adults again appear to be parasitic mainly on wild and feral pigs (Wassef and Hoogstraal 1986).

Unfortunately, adults of an undescribed species of tick probably assignable to the genus, Amblyomma, collected by Durden (1986) as a single nymphal specimen (Accession No. HH112,315 in the Hoogstraal tick collection is now housed at the Smithsonian Institution, Washington D.C., USA) from a murid, $M$. musschen-broekii, in Sulawesi Utara, were not collected. This immature specimen is so atypical that Hoogstraal (personal communication) could not be certain of its taxonomic status and hopefully, future ectoparasite collections from Sulawesi will produce adults of this fascinating tick.

Analysis of the prevalence of tick infestation from the murid species examined shows that no ticks were taken from the 13 Bunomys fratrorum or from the 11 congeneric B. chrysocomus rats processed. The other five murid species showed various levels of infestation. Rattus hoffmanni $(\mathrm{n}=10)$ showed a collective tick (three genera represented) prevalence of $40 \%$ and a mean intensity of 3.0 ticks per infested animal. The other murid species had the following comparable infestation figures:

$R$. xanthurus $(\mathrm{n}=7)(1$ tick genus), 14.3\%, 2.0;

$P$. dominator $(\mathrm{N}=16)(2$ tick genera), 31.3\%, 3.4;

M. musschenbroekii $(\mathrm{n}=17)(3$ tick genera), $23.5 \%, 4.8$;

M. hellwaldii ( $\mathrm{n}=11)(1$ tick genus), 9.1\%, 4.0.

The main difference between these data and those of Durden (1986) is that, in this study, no Dermacentor (Indocentor) sp. ticks were collected from murids. In the earlier survey, B. fratrorum and especially M. musschenbroekii were quite heavily infested by ticks of this subgenus; this difference could reflect a seasonal influence. Another difference, possibly attributable to phenology, is the presence of Ixodes sp. immatures from murids trapped in the lowland forests (200-300 m elevation) of Dumoga-Bone National Park in this collection; Durden (1986) did not record this genus from murids from comparable elevations in this forest. The earlier collection (Durden 1986) was made from January to March, 1985, during the latter part of the monsoon season (although heavy rains were not as concentrated into this season as is typical for much of Southeast Asia).

\section{ACKNOWLEDGMENTS}

Deep gratitude is extended to Dr. I.E. Keirans who identified the ticks described here and to Dr. G.G. Musser for confirming host identities. Appreciation is also extended to R.G. Robbins for cataloguing ticks, to Dr. N.A. Wilson for sup- 
plying separates and to the late Dr. H. Hoogstraal for his personal communications and earlier tick identifications. This research was undertaken as part of Project Wallace organized by the Royal Entomological Society of London and the Indonesian Institute of Sciences (Results of Project Wallace No. 30).

\section{REFERENCES}

ANASTOS, G., 1950. The scutate ticks, or Ixodidae, of Indonesia. Entomol. Am., 30: 1.

DURDEN, L.A., 1986. Ectoparasites and other arthropod associates of tropical rain forest mammals in Sulawesi Utara, Indonesia. Nat. Geogr. Res., 2: 320.

KEMP, D.H. and WILSON, N.A., 1979. The occurrence of Amblyomma cyprium (Acari; Ixodidae) in Australia, with additional records from the Southwest Pacific. Pac. Insects, 21: 224.

KOHLS, G.M., 1957. Insects of Micronesia. Acarina: Ixodoidea. Insects Micronesia, 3: 85.

MARSHALL, A.G., 1976. Host specificity amongst arthropods ectoparasitic upon mammals and birds in the New Hebrides. Ecol. Entomol., 1: 189.

VAN PEENAN, P.F.D., CARNEY, W.P., SUDOMO, M. and SULIANTI SAROSO, J., 1974. Parasites of mammals in Gumbasa valley, Central Sulawesi, Indonesia. Trop. Geogr. Med., 26: 352.

WASSEF, H.Y. and HOOGSTRAAL, H., 1986. Dermacentor (Indocentor) steini (Acari: Ixodidae): Identity of male and female. J. Med. Entomol., 23: 532.

WILSON, N.A., 1969. Ticks (Metastigmata: Ixodidae) collected by the Noona Dan expedition to the Philippine and Bismarck archipelagos. Entomol. Med., 37: 285. 